\title{
Solar Water Pumping System Control Using a Low Cost ESP32 Microcontroller
}

\author{
Shatadru Bipasha Biswas \\ Department of Electrical \& Computer Engineering \\ Faculty of Engineering \& Applied Science \\ Memorial University of Newfoundland \\ St. John's, NL, Canada \\ E-Mail: sbb278@mun.ca
}

\begin{abstract}
This paper presents a low cost automated solar water pumping system for irrigation in developing countries. The programmed sensor module detects the temperature, humidity, soil moisture level and sends the information to ESP32 microcontroller. A water level sensor also observes the water level and sends the data to the microcontroller unit. Based on the information and boundary conditions, the microcontroller decides either to start or to stop the pump motor. This paper also describes how to decide soil moisture limits for a particular type of soil. The ESP32 microcontroller also sends results to the webserver so that the user can see that. The user can operate the irrigation system far from the field by a simple click on a cellphone. A manual ON/OFF system is also incorporated into the proposed design.
\end{abstract}

Keywords-ESP32 microcontroller; HiGrow sensor module; DHT11 sensor, soil moisture sensor; solar water pumping.

\section{INTRODUCTION}

Bangladesh is a densely populated agriculture-based country whose more than $50 \%$ cultivable lands need irrigation because monsoon-based cultivation cannot meet the challenge [1]. According to Bangladesh Agricultural Development Corporation (BADC), there were 1.71 million pumps in Bangladesh in 2012; 83\% diesel operated and 17\% electrically operated [2]. Gopal, Mohanraj, Chandramohan, and Chandrasekar [3] stated that solar photovoltaic water pumping systems are the most widely used renewable energy source application for irrigation and domestic use. Aligah [4] described some advantages of solar PV system like unattended operation, low maintenance, easy installation and long life. The author also did the Life Cycle Cost (LCC) analysis for twenty years of period and found that the solar energy system was cheaper to operate although the initial cost was high for it. Moreover, for consecutive three season's irrigations, the unit cost of water is cheaper in case of PV water pumping system comparing with diesel engine system [5]. Bangladesh is blessed with enormous solar resources because of geographical location. The Government of Bangladesh is promoting alternative sources of energy to meet the energy deficiency. Many Governmental and NonGovernmental organizations are encouraging people to go with renewable sources of energy.

\author{
M. Tariq Iqbal \\ Department of Electrical \& Computer Engineering \\ Faculty of Engineering \& Applied Science \\ Memorial University of Newfoundland \\ St. John's, NL, Canada \\ E-Mail: tariq@mun.ca
}

Harishankar, Kumar, Sudharsan, Vignesh, and Viveknath [6] recommended a controlled irrigation system in which the outlet valve of the tank was automatically regulated using a controller and moisture sensor to control the flow rate of the water from the tank to the irrigation field. Uddin et al. [7] proposed an automatic irrigation system using a microcontroller. The designed sensor could be able to detect the water level in the paddy field and according to the sensor data, the pump was operated automatically. Dursun and Ozden [8] described a low-cost wireless controlled drip irrigation system. A pre-calibrated soil moisture sensor used to measure the dielectric constant of the soil to find the soil moisture content. A base station unit was controlling the valves by digital outputs of the microcontroller to water the plants according to the sensor data. Oi, Anwari, and Taufik [9] designed a standalone battery less DC solar PV water pumping system for small scale operation incorporated with Maximum Power Point Tracker (MPPT). The authors concluded that the MPPT improved the efficiency of the system significantly.

Malla, Bhende, and Mishra [10] designed a stand-alone PV water pumping system without battery storage and simulated in MATLAB/Simulink. The speed control of the induction motor was based on vector control and the authors found satisfactory results for both single and multi-motor type system. Arrouf and Ghabrour [11] modelled and simulated a pumping system fed by a PV generator in MATLAB/Simulink. Katan, Agelidis, and Nayar [12] showed that the performance of a PVDC system could be increased by using MPPT and Sun tracker.

A low cost automated irrigation system using microcontrollers is missing in the literature. We present a detailed control system of an automatic solar PV water pumping system for irrigation. A simple and quite low cost modern ESP32 controlled irrigation system is presented here which is affordable for farmers in developing countries. The proposed system can improve the traditional irrigation system by lowering its cost and has features compatible with current technology.

For designing and sizing estimation, the necessary site data were collected from an existing Solar Irrigation Pumping System (SIPS) project which is situated in Bangladesh. 


\section{Methodology}

The main objective of this paper is to design and demonstrate a controlled solar water pumping system for irrigation in Bangladesh. A solar irrigation pumping system consists of solar Photo Voltaic (PV) array, inverter, motorpump set, and storage system. There are two types of the storage system; energy storage in batteries and water storage in a large tank. This paper will proceed with the second alternative. System sizing was carried out by HOMER (Hybrid Optimization and Multiple Energy Recourses). The proposed system can be explained through Fig.1.

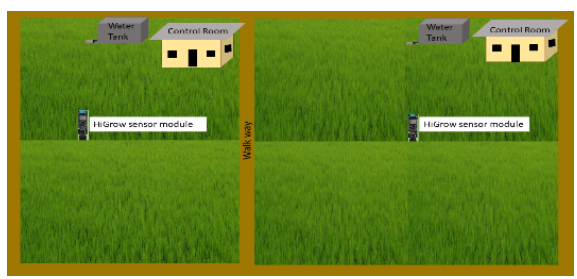

Fig. 1. Proposed System

If a HiGrow sensor module is installed in the field after uploading the control code, it will detect the field parameters i.e. temperature, humidity, soil moisture and send the information to the webserver. A water level sensor will also check the water level in the tank and send details to the webserver. The water pump motor operates automatically according to the sensor data. The user can also operate the motor by clicking the on/off button created on webserver page which is easily accessible through any cellphone. There is also a manual switch to control the motor run time. The user does not need to visit the fields to check whether the crops need irrigation or not. He can also control the whole irrigation system by sitting at home or if he is away from the field.

\section{SyStem SIZING}

Sizing of the proposed solar irrigation pumping system was done using HOMER. Daily load data (Fig.2), solar irradiance (Fig.3) and temperature (Fig.4) of that selected site were collected for optimization. The system was designed to lift maximum of $1930 \mathrm{~m}^{3}$ of water per day with an average discharge of $241.25 \mathrm{~m}^{3} / \mathrm{h}$.

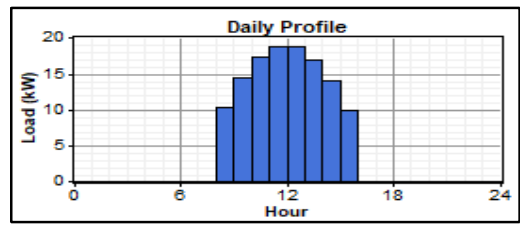

Fig. 2. Daily Load Data

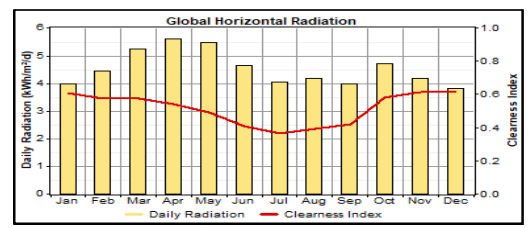

Fig. 3. Irradiance

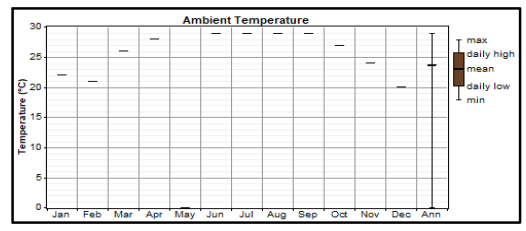

Fig. 4. Temperature

HOMER Optimization result for battery-based system is stated in TABLE I. Price of PV, battery storage and inverter were collected from various websites and used in HOMER.

TABLE I. SYSTEM COMPONENTS

\begin{tabular}{|l|l|}
\hline \multicolumn{1}{|c|}{ System component } & \multicolumn{1}{c|}{ Rating } \\
\hline PV $[\mathrm{kW}]$ & $38.4($ each module 310 Wp $)$ \\
\hline Battery Storage $[\#]$ & $60(12 \mathrm{~V}, 200$ Ahr each) \\
\hline Inverter $[\mathrm{kW}]$ & 20.7 \\
\hline
\end{tabular}

Water storage tank equivalent to battery storage was calculated manually and concluded with the tank size of 3100 cubic meter. To find out the entire system cost, total cost of the water tank storage was calculated accordingly [13]. The economic cost breakdown is shown in Fig.5.

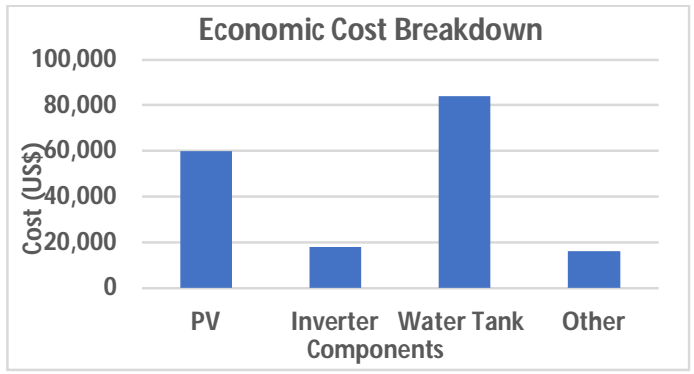

Fig. 5. Economic Cost Breakdown

Although the system is designed for maximum ground water extraction, the amount of lifted water per day varies due to variation of solar radiance. From June to September the produced electricity would be lower (Fig.6) because the recorded Solar Irradiance become lower in these months.

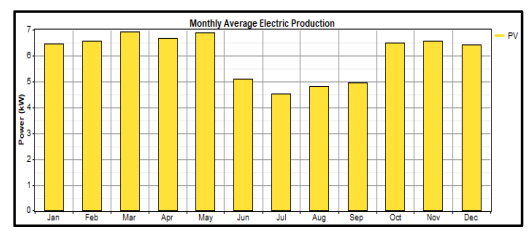

Fig. 6. Monthly Average Electric Production

The designed system can produce a total of $52,804 \mathrm{kWh}$ energy per year with only $15.2 \%$ excess electricity. The output from PV array ranges from $7.2 \mathrm{~kW}$ to $28.8 \mathrm{~kW}$ while it is running. The mean PV output is about $145 \mathrm{kWh} / \mathrm{d}$ with the capacity factor of $15.7 \%$. A $20.7 \mathrm{~kW}$ inverter is used to convert the DC photovoltaic output into AC unit. 


\section{ESP32 AND HigRow SENSOR Module}

Water pumping system can be controlled using programmable logic circuits (PLC) and microcontrollers. Such arrangements cost 100's of dollars and suffer from maintenance issues in developing countries.

ESP32 was introduced by Espressif System which is a successor to the ESP8266 microcontroller [14]. It is a low cost, low power system on a chip microcontroller with integrated $\mathrm{Wi}-\mathrm{Fi}$, dual mode Bluetooth capabilities and power saving features which made it more versatile. ESP32 is compatible with mobile devices and IoT (Internet of Things) applications. It turned out as a reliable option in an industrial environment because of the wide operating temperature range. This microcontroller can act as a complete standalone system or can be operated as a slave device to a host microcontroller.

The HiGrow sensor module is a temperature, humidity and soil moisture, sensor (Fig7). It can communicate with cloud application to upload sensor data so that the user can check field condition through any browser. It can also be connected to webserver which is responsible for returning a web page to the client when the client is connected to it through HTTP (Hypertext Transfer Protocol). For the temperature and humidity, a sensor module DHT11 is attached with the HiGrow plant monitor. The ESP32 is connected to DHT11 to read temperature and humidity values which are routed to pin 22 .

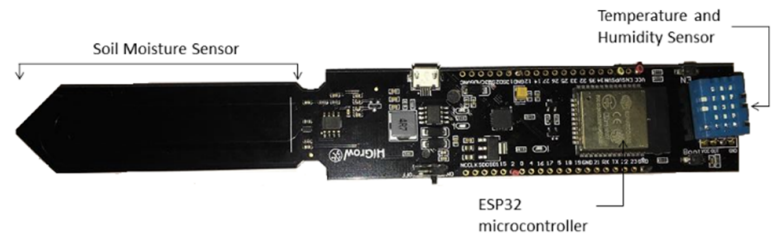

Fig. 7. HiGrow Sensor Module

The pointed edge of the HiGrwo module is moisture sensor which monitors the soil moisture level. This moisture sensor is capacitive type. The capacitor is electrically connected with two small resistors. As the water almost touches the sensor, the dielectric constant of the material between the capacitor plates changes which forces the timer to run at a different frequency. There is a $\mathrm{RC}$ oscillator on the output of the timer which effectively generates relatively stable analog voltage. The generated analog voltage is routed to pin 32. ESP32 comes with an ESP-Wroom-32 microntroller. According to Espressif System, The ESPWroom-32 is a powerful microcontroller module with generic $\mathrm{Wi}-\mathrm{Fi}$ and Bluetooth Low Energy (BLE) which has a wide variety of applications. A LG 3000mAh 18650 battery could make ESP32 to run 17 hours or more.

\section{Proposed Control System}

The proposed control system is based on the ESP32 microcontroller. Fig. 8 gives an idea about experimental setup of the system. $38.4 \mathrm{kWp}$ solar array produces necessary direct current (DC) energy and a $20.7 \mathrm{~kW}$ solar inverter converts this variable DC output into utility frequency alternating current (AC unit). This $\mathrm{AC}$ power is used to run motor pump set for ground water extraction. Then the lifted water is stored in a large water tank to irrigate the field. A ESP32 microcontroller is used to control the motor operation based on the field conditions. The ESP32 can be programmed using Arduino software, freely available at arduino.cc. Esp32 control code is commonly referred as sketch. The HiGrow plant monitor senses the temperature, humidity, soil moisture and sends the data to ESP32. The tank water level sensor is connected to ESP32 and sends information about water tank. The output of the microcontroller is connected to a normally open (NO) type relay to control the motor pump operation. The microcontroller controls the motor operation by sending trip signal to the relay.

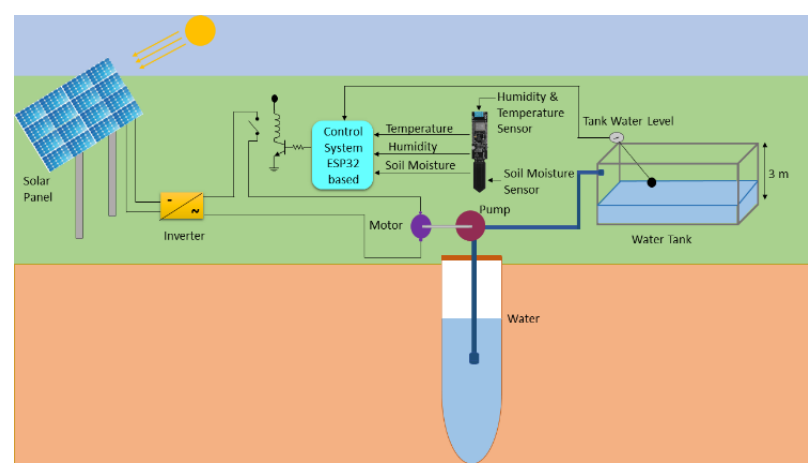

Fig. 8. Proposed Control System

Here in this paper, a $10 \mathrm{~K}$ potentiometer is represented as the tank water level sensor. The potentiometer reading is mapped into the tank water level in the scale from $0 \mathrm{~m}$ to $3 \mathrm{~m}$ as the height of the tank was decided as $3 \mathrm{~m}$. The following Fig. 9 describes this mapping in a better way.

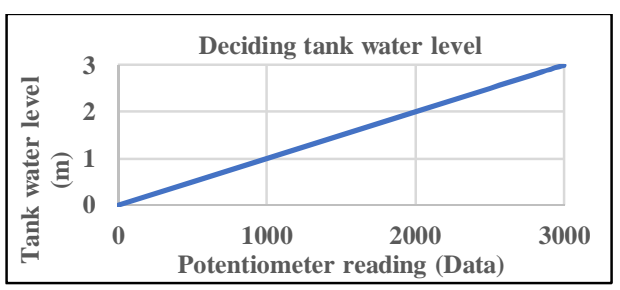

Fig. 9. Mapping Potentiometer Reading into Tank Water Level

The capacitive soil moisture sensor in HiGrow sensor module gives the output voltage $(\mathrm{mV})$ reading from the low pass filter. To decide the moisture level limits, the various percentage of water was added to a particular type of soil and tested the output voltage values of soil moisture sensor. This experiment was done with $300 \mathrm{gm}$ engineered soil (potting mix) which had $36.2 \%$ moisture content initially. Then water was added to the soil up to $549.6 \%$ to make it slurry and the output voltages were recorded accordingly. Moisture contents (\%) were calculated from (1).

$$
\theta=\left(\mathrm{W}_{\mathrm{w}} / \mathrm{W}_{\mathrm{s}}\right) \times 100 \%
$$

Where, $\theta=$ moisture content, 
$\mathrm{W}_{\mathrm{w}}=$ mass of the water

$\mathrm{W}_{\mathrm{s}}=$ mass of the soil

The output voltage in the air is $3383 \mathrm{mV}$ and in the clear water $1700 \mathrm{mV}$. Fig. 10 shows the mapping of output voltage for various soil moisture.

When more than $200 \%$ water was added to the soil, the output voltage of the slurry and clear water became consistent. From the output voltage, the user can know about the soil moisture content. While programming the ESP32 using Arduino 1.8.5 software, the boundary limits for tank water level and soil moisture content were decided from Fig.9 and Fig. 10.

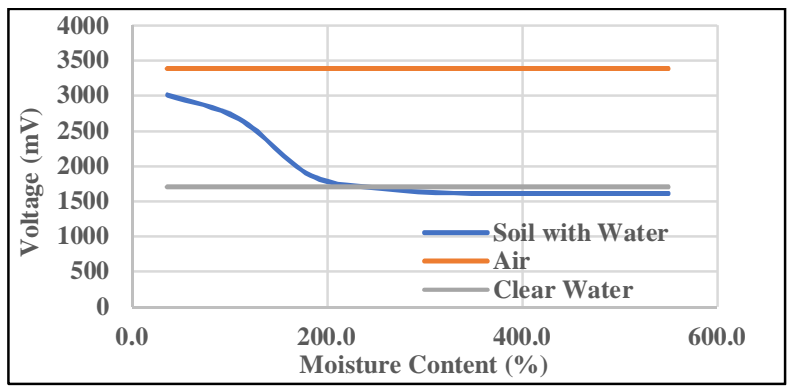

Fig. 10. Deciding Moisture Content limit

Based on the temperature, humidity, soil moisture content and tank water level, the microcontroller takes the decision whether to run the motor or not. The microcontroller continuously checks the soil moisture, temperature, humidity and tank water level accordingly. If the soil moisture content becomes less than the expected value, ESP32 checks the temperature and humidity. If the temperature becomes greater than the preferred value and humidity less than the selected value, the microcontroller finally checks the tank water level. If the tank water level becomes less than the chosen value, the ESP32 sends the trip signal to the relay to run the water pump motor. After running for two hours, the motor will stop working automatically. If any of the above conditions becomes false before completing the run time, the ESP32 will send the signal to disconnect the circuit. As a result, the motor will stop working as soon as possible. The motor will remain in idle mode till all the conditions become true. In this paper, a built in LED of the HiGrow module represents the motor state. The built in LED is connected to pin13. The control block diagram is presented in the following Fig. 11. The ESP32 microcontroller also sends the sensor data to a webserver. There are two buttons created in the webserver page. By clicking on those buttons, the user will also be able to control the motor. There is also a manual on/off switch to control the motor.

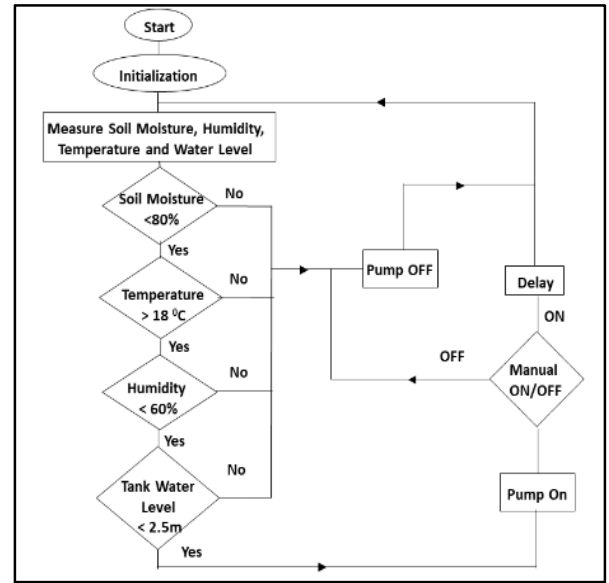

Fig. 11. Flow Chart

\section{EXPERIMENTAL RESULTS}

After uploading the Arduino sketch, the soil moisture sensor of HiGrow sensor module was inserted into the dry soil. The module was powered from a USB port connected to a laptop. Fig. 12 shows the testing of proposed control design.

Webserver running on ESP32 can be accessed from any browser on a cell phone or on a computer. IP address of the webserver was printed on the serial monitor screen. This IP address navigates to the webserver through a web browser. The user can check the status through cell phones also. Fig.13(a) shows the webserver page when the soil is dry. After adding some water to the soil Fig.13(b) shows that the reading has changed in webserver page. By clicking the ON button, the motor can be turned on and the motor can be turned off by clicking the OFF button.

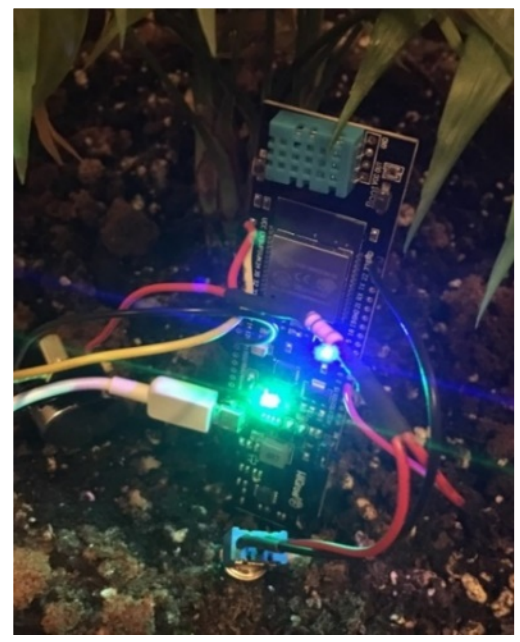

Fig. 12. Testing

The following webserver pages show temperature (both Celsius and Fahrenheit scale), humidity (\%), soil moisture content $(\%)$ and tank water level $(\mathrm{m})$ for both $\mathrm{ON}$ and $\mathrm{OFF}$ conditions. 


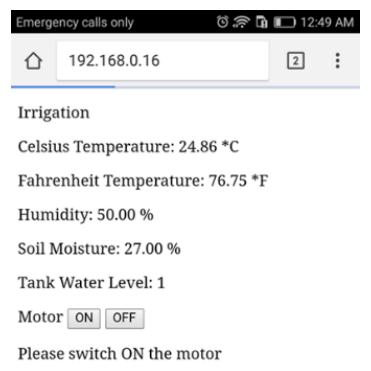

Fig. 13. Dry Soil

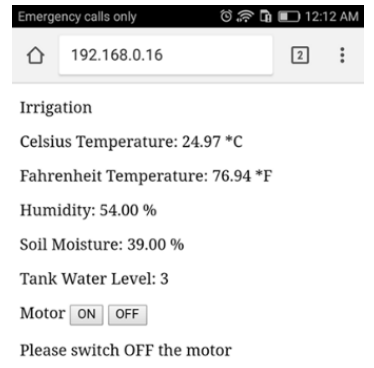

Fig. 14. Wet Soil

\section{CONCLUSIONS}

The proposed control system is for a low cost automated solar irrigation pumping system which is a modest solution for farmers in developing countries. Most of the time the farmers check the soil moisture content by visiting the field and estimation. The recommended system is more convenient because it is not necessary for the users to visit the field each time to take the decision whether to run the motor or not. This system is time saving and ensures lowest water wastage.

The HiGrow sensor module has capacitive soil moisture sensor which is different from most of the resistive sensors available in the market because resistance sensors are easy to corrode.

While deciding the moisture content limit through output voltage, only one type of engineered soil (potting mix) was considered. Moreover, the soil had mineral contents. So, this calculated soil moisture limit would not be applicable for all kinds of soil or crops. Soil moisture limit would vary from soil to soil, crop to crop. As an example, the soil needs to be fully saturated before harvesting period for the cultivation of Boro (mostly irrigated and high yielding rice in Bangladesh). It is highly recommended to test the soil moisture limits before installing this system. The boundary condition for temperature and humidity also vary from place to place.

Selected ESP32 microcontroller and sensor module cost about US\$10 that is extremely lower than the cost of PLC used in most of the water pumping systems. The cost of commercial water pumping system controller is about US\$1000. The proposed system is extremely low cost automatic solar irrigation pumping system that could be used in developing countries.

\section{ACKNOWLEDGMENT}

The author would like to acknowledge NSERC and MUNSGS for providing funding for this research.

\section{REFERENCES}

[1] Shahidul I Khan, Md. Mizanur R. Sarkar, and Md. Quamrul Islam, "Design and analysis of a low cost solar water pump for irrigation in Bangladesh" Journal of Mechanical Engineering, Vol ME 43, NO. 2, December 2013.

[2] Bangladesh Agricultural Development Corporation (BADC), Shech Bhavan, Dhaka, "Summary of irrigation equipment used, area irrigated and benefited farmers:2010-2011", 2012.

[3] C. Gopal, M. Mohanraj, P. Chandramohan, and P. Chandrasekar, "Renewable energy source water pumping systems-A literature review", Renewable and Sustainable Energy Reviews 25 (2013) 351370, 2013.

[4] M. Abu-Aligah, "Design of photovoltaic water pumping system and compare it with diesel powered pump", Jordan Journal of Mechanical and Industrial Engineering, Vol 5, No. 3, pp.273-280, June 2011.

[5] Mohammed Mozammel Hoque, "Photovoltaic water pumping system for irrigation", $4^{\text {th }}$ International Conference on Mechanical Engineering, Dhaka, Bangladesh, pp. I 21-26, December 2001.

[6] S. Harishankar, R Satish Kumar, Sudharsan K.P, U. Vignesh, and T Viveknath, "Solar powered smart irrigation system", Advance in Electronic and Electric Engineering, Vol. 4, No. 4, pp. 341-346, 2014.

[7] Jia Uddin, S.M. Taslim Reza, Qadar Newaz, Jamal Uddin, Touhidul Islam, Jong-Myong Kim, "Automated irrigation system using solar power", $7^{\text {th }}$ International Conference on Electrical and Computer Engineering, Dhaka, Bangladesh, December 2012.

[8] Mahir Dursun, Semih Ozden, "A wireless application of drip irrigation automation supported by soil moisture sensor", Scientific Research and Essays Vol.6(7), pp. 1573-1582, April 2011.

[9] Taufik, Akihiro Oi, Makbul Anwari, Mohammad Taufik, "Modelling and simulation of photovoltaic water pumping system", Third Asia International Conference on Modelling \& Simulation, 2009.

[10] S. G. Malla, C. N. Bhende, S. Mishra, "Photovoltaic based water pumping system", IEEE, 2011

[11] M. Arrouf, S. Ghabrour, "Modelling and simulation of a pumping system fed by photovoltaic generator within the Matlab/Simulink programming environment", The Ninth Arab International Conference on Solar Energy (AICSE-9), Kingdom of Bahrain, Science Direct, Desalination 209 (2007) 23-30, 2007.

[12] Katan RE, Agelidis VG, Nayar CV, "Performance analysis of a solar water pumping system", In: Proceedings of the 1996 IEEE international conference on power electronics, drives, and energy systems for industrial growth (PEDES); p.81-7, 1996.

[13] Ms. Snehal R. Metkar, Prof A. R. Mundhada, "Economics of R.C.C water tank resting over firm ground vis-a-vis pre-stressed concrete water tank resting over firm ground", engineeringcivil.com.

[14] ESP32 Technical Reference Manual, Version 2.8, Espressif system, \#101, Block2, 690 Bibo Road, Zhangjiang High-Tech Park, Pudong, Shanghai, China 201203, 2018. 